\title{
A SEXUALIDADE INFANTIL EM DESTAQUE: ALGUMAS REFLEXÕES A PARTIR DA PERSPECTIVA FREUDIANA
}

\author{
LA SEXUALIDAD INFANTIL EN DESTAQUE: ALGUNAS REFLEXIONES DESDE \\ DE LA PERSPECTIVA FREUDIANA
}

\author{
INFANTILE SEXUALITY HIGHLIGHTED: SOME REFLECTIONS FROM THE \\ FREUDIAN PERSPECTIVE
}

Ivonicleia Gonçalves BOROTO ${ }^{1}$ Regina Célia Mendes SENATORE ${ }^{2}$

RESUMO: O presente artigo é um estudo embasado na análise bibliográfica e tem por objetivo discutir um dos principais fundamentos da teoria psicanalítica freudiana: a sexualidade infantil. No início do século XX Freud causa impacto ao apresentar a criança como um ser dotado de sexualidade e ao apontar a importância da sexualidade para a constituição do sujeito. Freud amplia o conceito de sexualidade, afirmando que a mesma é inerente ao sujeito. A partir de tal perspectiva o termo sexualidade necessita ser diferenciado da noção de genitalidade, comumente empregada ao termo. Na concepção freudiana a sexualidade infantil é caracterizada como perverso-polimorfa e autoerótica. Freud afirma também que a criança é bissexual. Ao longo do artigo são também discutidos os conceitos de complexo de Édipo e amnésia infantil na visão freudiana, bem como a necessidade e a importância do esclarecimento sexual para as crianças.

PALAVRAS-CHAVE: Sexualidade. Sexualidade infantil. Freud. Psicanálise. Psicologia da educação.

RESUMEN: El artículo es un estudio basado en el análisis bibliográfico y tiene el objeto de discutir uno de los principales fundamentos de la teoría psicoanalítica freudiana: la sexualidad infantil. En el comienzo del siglo XX Freud causa impacto al presentar el niño como un ser dotado de sexualidad y al señalar la importancia de la sexualidad para la constitución del sujeto. Freud amplía el concepto de sexualidad, afirmando que ella es inherente al sujeto. Desde de tal perspectiva el término sexualidad necesita ser diferenciado de la noción de gentilidad, como perverso-polimorfa y auto erótica. Freud afirma también que el niño es bisexual. A lo largo del artículo son también discutidos los conceptos de complexo de Edipo y amnesia infantil en la visión freudiana, así como la necesidad y la importancia del esclarecimiento sexual para los niños.

PALABRAS CLAVE: Sexualidad. Sexualidad infantil. Freud. Psicoanalice. Psicología de la educación.

\footnotetext{
${ }^{1}$ Universidade Federal do Espírito Santo (UFES), São Mateus - ES - Brasil. Mestranda em Ensino na Educação Básica. Centro Universitário Norte do Espírito Santo - Programa de pós-graduação em Ensino na Educação. ORCID: <http://orcid.org/0000-0002-2495-3303>.E-mail: ivoniboroto@yahoo.com.br

${ }^{2}$ Universidade Federal do Espírito Santo (UFES), São Mateus - ES - Brasil. Professora Doutora. ORCID: <http://orcid.org10000-0001-7771-6742>. E-mail: rcsenatore@gmail.com
} 
ABSTRACT: This article is a study based on bibliographic analyses. It aims to discuss one of the main principles of Freudian psychoanalytical theory: infantile sexuality. In the early 20th century Freud impacts when he introduces the child as a being with sexuality and also when he highlights the importance of the sexuality to the human's formation. Freud broadens the concept of sexuality when he affirms that it is inherent to human being. From the Freudian's perspective the term sexuality needs to be differentiated from the genital notion, commonly used to the term. In Freud's conception, the infantile sexuality is polymorphous-perverse and autoerotic. Freud also says that child is bisexual. In the article are also discussed the concepts of Oedipus complex and child amnesia in Freud's view as well as the need and the importance of the sexual enlightenment of children.

KEYWORDS: Sexuality. Infantile sexuality. Freud. Psychoanalysis. Educational psychology.

\section{Introdução}

A sexualidade tem sido, no senso comum, impregnada pelo reducionismo que a conceitua apenas como sinônimo de genitalidade e de reprodução. E assim o foi, por muito tempo, também nos meios acadêmicos.

Tem sido, ao longo do tempo, um tema de conceituação e aceitação problemáticos e complexos. Alvo de censuras, tabus, distorções e tentativas de reduzi-la meramente às questões de reprodução e genitalidade. Aliás, tal visão é comum até os dias de hoje.

$\mathrm{Na}$ verdade, a conceituação de sexualidade vai depender da postura que se adota diante da mesma, podendo ser, dentre outras, a visão psicológica, antropológica, biológica. Adotaremos, aqui, a perspectiva Psicanalista freudiana sobre sexualidade humana, em especial sua visão de sexualidade infantil.

Sigmund Freud confere à sexualidade um sentido bem mais amplo do que o aceito comumente. De acordo com a psicanálise - que estuda o homem moderno ocidental -, a sexualidade é constitutiva da subjetividade humana. Aqui, a mesma ultrapassa a mera questão da reprodução e se caracteriza por não ser reduzida apenas às atividades prazerosas que dependem unicamente do aparelho genital.

A propósito, a sexualidade compreende uma gama de excitações e desejos presentes do indivíduo desde sua infância. É possível percebê-las em atividades como na sucção do lactente, na retenção e expulsão de excrementos, nos exibicionismos, na manipulação dos genitais, dentre outras. Por intermédio de tais atividades o corpo vai se tornando erotizado, desde a infância, em diferentes áreas, consideradas zonas erógenas. 
Para a Psicanálise a sexualidade não se limita ao corpo biológico, pois é produzida por experiências psíquicas inconscientes. Tanto que a Psicanálise relaciona as vivências da sexualidade infantil ao aparecimento de neuroses na vida adulta.

A criança, desde a mais tenra idade, manifesta curiosidades relacionadas à sexualidade, lançando-se às observações e investigações sexuais. E de acordo com Maria Cristina Machado Kupfer, as "[...] primeiras investigações são sempre sexuais e não podem deixar de sê-lo: o que está em jogo é a necessidade que tem a criança de definir, antes de mais nada, seu lugar no mundo. E esse lugar é, a princípio, um lugar sexual” (KUPFER, 2007, p. 81).

A primeira formulação psicanalítica sobre a sexualidade é elaborada por Freud em 1905, na obra "Três ensaios sobre a teoria da sexualidade". O autor dedica o segundo ensaio à sistematização da sexualidade infantil.

\section{Contribuições de Freud para a conceituação psicanalítica de sexualidade}

Ao longo dos séculos inúmeros discursos foram sendo formulados em torno do tema sexualidade. A cada momento histórico, tais discursos foram sendo apresentados como verdades ditadas ora pelo Estado, pela Igreja ou pela medicina que, através de discursos ideológicos, foram determinando o que deveria ser considerado "normal".

No século XX, em meio ao discurso médico e psiquiátrico, surge a psicanálise, fruto da cultura ocidental. Seu fundador e maior expoente é Freud, que irá, em 1905, sistematizar, pelo viés da psicanálise, o conceito de sexualidade.

A princípio, Freud - por meio da clínica e relato de histéricas - imaginou que a sexualidade era despertada na criança por meio de um adulto abusador. A partir de tais relatos Freud formula a teoria da sedução, em que o adulto investe na criança. Com o tempo percebe que o abuso não havia acontecido e que se tratava, na verdade, de uma fantasia (realidade psíquica). Freud então deixa de lado a teoria da sedução para tratar da fantasia, abrindo, assim, espaço para grandes descobertas relacionadas à sexualidade infantil.

Com o surgimento da Psicanálise e das descobertas freudianas há uma mudança de paradigma na concepção de sexualidade como era considerada até então.

A sexualidade passa a ser considerada de grande importância, considerada como essência da atividade humana, sendo reconhecida como ponto de referência para a formação do psiquismo humano.

A concepção de sexualidade proposta amplia os conceitos que se tinham até então. A definição agora formulada difere em muito da noção aceita de instinto sexual. Para Freud a 
sexualidade humana não é em nada instintiva. Ele afirma que o ser humano, desde a infância, busca prazer e satisfação de variadas formas. A busca pelo prazer não se direciona apenas aos órgãos genitais e a reprodução não é seu único objetivo.

No artigo "Três ensaios sobre a teoria da sexualidade", de 1905, estabelecendo que a sexualidade não deve ser tratada como instinto (comportamento animal definido pela hereditariedade), Freud introduz o termo pulsão (Trieb). A presença de necessidades sexuais se manifesta por meio de pulsões e tais pulsões são de natureza sexual, designadas libido.

O princípio do conceito de sexualidade para Freud é de que toda pulsão é pulsão sexual. Pulsão significa energia, são impulsos psíquicos que conduzem o comportamento humano. Energia, por sua vez, é aqui considerada como libido, que é a pulsão de vida, a energia das pulsões sexuais.

Com relação à pulsão sexual, Freud fala da existência de pulsões parciais, em sua maioria associadas a uma zona erógena, que são partes do corpo que proporcionam sensações prazerosas.

De acordo com Freud sexual difere do termo genital. Assim, é necessário entender o pensamento de Freud em relação ao que seja considerado sexual. De acordo com Maria Cristina Machado Kupfer,

Em seu pensamento, sexual não se confunde com genital. A sexualidade genital refere-se precisamente à cópula com o objetivo de procriar ou de obter prazer orgástico. Mas a sexualidade é mais ampla que a sexualidade genital. Inclui as preliminares do ato sexual, as perversões, as experiências sexuais da criança vividas em relação ao seu próprio corpo ou em contato com o corpo da mãe (KUPFER, 2007, p. 39)

Freud causa certo impacto ao afirmar, em 1905, a existência e a presença da sexualidade desde a infância e também ao apontar a importância e o determinismo da sexualidade para a constituição do sujeito. Freud salienta a centralidade da sexualidade em aspectos do desenvolvimento humano.

No segundo dos "Três Ensaios", Freud surpreende - e causa certo espanto - com a teoria de uma infância portadora de sexualidade e também de que as experiências e condutas sexuais infantis interferem na vida e no comportamento da pessoa adulta. De acordo com Freud os pequenos possuem desejos e fantasias sexuais.

As afirmações de Freud sobre a existência e a presença da sexualidade desde a mais tenra idade não deixariam de repercutir em uma época em que a concepção que se tinha de criança era de que a mesma seria um ser "inocente" e desprovido de sexualidade. Segundo o autor, 
Faz parte da opinião popular sobre a pulsão sexual que ela está ausente na infância e só desperta no período da vida designado puberdade. Mas esse não é apenas um erro qualquer, e sim um equívoco de graves consequências, pois é o principal culpado de nossa ignorância de hoje sobre as condições básicas da vida sexual [...] (FREUD, 1989a, p. 162)

Apesar da moral repressora de sua época, Freud afirma e defende o pluralismo que compõe a sexualidade que tem início desde a infância. Mesmo tendo sido proferidas por há mais de cem anos, as palavras de Freud, acima citadas, ainda soam como atuais.

\section{A concepção freudiana de sexualidade infantil}

Durante investigações clínicas sobre causas das neuroses, Freud descobriu, a partir do relato de pacientes, que a grande maioria dos desejos e dos pensamentos reprimidos decorria de conflitos de ordem sexual, que remetiam aos primeiros anos de vida dos indivíduos. Notou que experiências traumáticas, reprimidas da vida infantil, deixavam grandes marcas na composição da personalidade e originavam sintomas na vida adulta.

A partir de tais descobertas, que colocam a sexualidade como central na vida psíquica, Freud desenvolve, em 1905, no segundo artigo dos "Três ensaios" a teoria psicanalítica da sexualidade infantil. Nele, Freud atribui a importância da sexualidade infantil para todas as ações futuras do sujeito.

Quanto à presença da sexualidade desde a mais tenra idade, Freud afirma que "[...] o recém-nascido traz consigo germes de moções sexuais que continuam a se desenvolver por algum tempo [...]" (FREUD, 1989a, p. 165).

Na obra "O esclarecimento sexual das crianças", de 1907, Freud complementa afirmando que

[...] Na realidade o recém-nascido já vem ao mundo com sua sexualidade, sendo seu desenvolvimento na lactância e na primeira infância acompanhado de sensações sexuais; só muito poucas crianças alcançam a puberdade sem ter tido sensações e atividades sexuais [...] (FREUD, 1989b, p. 139)

Portanto, a reflexão sobre a sexualidade infantil remete para a importante contribuição de Freud para a sexualidade do século XX. Freud postula - contra as tendências da época - uma infância provida de sexualidade. Para um período da história em que a infância era considerada dotada de "inocências", as afirmações de Freud sobre a existência de uma sexualidade infantil não deixaram de ter grande repercussão. 
Ao tratar da sexualidade infantil é necessário relembrar que há distinção entre os termos sexual e genital, pois para Freud, como já dito, sexualidade não se restringe à atividade genital e nem mesmo à procriação apenas.

Freud afirma que ao nascer, a criança é só pulsão (energia, libido) e que tal pulsão é de origem sexual. O mesmo ressalta que a pulsão sexual (impulso sexual humano) pode decomporse em pulsões parciais, que são os aspectos perversos presentes na sexualidade infantil.

A pulsão sexual associa-se, desde o início da vida, à satisfação através do estímulo de uma zona erógena. Para que haja a necessidade de repeti-la a satisfação precisa ter sido antes vivenciada. Geralmente os estímulos das zonas erógenas estão inicialmente vinculados a funções fisiológicas vitais, como a alimentação, a defecação, a micção.

$\mathrm{Na}$ verdade, o corpo da criança é uma fonte inesgotável da sua sexualidade e de prazer, na medida em que ela vai sentindo o mundo por meio do mesmo, desde seu nascimento. Toda e qualquer a parte do corpo pode vir a tornar-se zona erógena, definida por Freud (1905) como parte da pele ou mucosa nas quais certos tipos de estímulos provocam sensação de prazer. Essas zonas erógenas são fontes de várias pulsões parciais (autoerotismo), determinando, em maior ou menor grau, certo tipo de meta sexual, que são fontes de prazer.

Uma das características da sexualidade infantil, segundo Freud, é ser bissexual. A pulsão, o prazer são da criança para com ela mesma, para com seu próprio corpo, sendo, assim, uma atividade autoerótica. A sexualidade infantil é a busca de prazer que pode ser por qualquer sexo. A criança é bissexual pois a sua sexualidade não é pré-determinada. A diferenciação homem/mulher só vai acontecer na fase genital, após o complexo de Édipo, que acontece na fase fálica.

Outra inovação freudiana foi reconhecer a disposição "perverso-polimorfa" que todos os seres humanos possuem. Freud denomina a sexualidade infantil como perverso-polimorfa, uma vez que se manifesta de várias formas, não havendo primazia de uma zona erógena determinada, afastando-se do modelo genital de relação sexual. As formas de obtenção de prazer derivam de qualquer área ou órgão do corpo, pois a sexualidade encontra-se, na infância, submetida à ação de pulsões parciais, que tendem a se incorporar apenas a partir da puberdade.

A partir da concepção de que o corpo é erotizado, ou seja, de que excitações sexuais localizam-se em partes do corpo (zonas erógenas), e que há um progressivo desenvolvimento das mesmas, com mudanças nas formas de gratificação sentidas pelo corpo em relação ao objeto, Freud chega à conclusão que o sujeito passa por fases de desenvolvimento sexual, já a partir do seu nascimento. 
Antes, vale ressaltar que, para Freud, a sexualidade infantil não é uma sequência de acontecimentos que ocorrem em tempo linear. São fases possíveis de serem observadas em determinadas épocas da infância. Segundo a teoria freudiana de sexualidade infantil, as fases de desenvolvimento infantil estão ligadas pelo deslocamento da libido para diferentes zonas erógenas. Por ter percebido certa organização nas pulsões sexuais infantis, Freud (1905) começa a agrupar tais pulsões em fases de desenvolvimento sexual infantil: fase oral, fase sádico-anal, fase fálica (incluída em 1923), período de latência e fase genital.

No desenvolvimento da sexualidade nenhuma fase é abandonada, apenas novas fases vão sendo somadas às outras.

A primeira demonstração da sexualidade infantil é a sexualidade oral. Na fase oral há a primazia da zona erógena bucal. A boca é o vínculo que a criança tem com o mundo nesta fase da vida. Por meio dela, a criança passa a conhecer e a provar o mundo externo. Toda a energia libidinal está, nesse momento, voltada para a boca. O objetivo sexual vincula-se à incorporação do objeto.

O princípio da satisfação da zona oral ancora-se em uma função fisiológica vital: a alimentação. Com o tempo, a necessidade de repetir o prazer encontrado no ato de mamar desvincula-se da necessidade pelo alimento. Pela necessidade de nutrição a atividade de sugar torna-se prazerosa e os lábios se transformam em uma zona erógena.

Freud descreve que a sucção do bebê é dotada de natureza sexual. Ao abandonar o seio materno o bebê começa a fantasia-lo, iniciando a atividade de sucção do próprio polegar. Assim, a criança dá início a sua atividade autoerótica, pois o seu próprio corpo é responsável pela satisfação recebida. Em tal prática a criança procura repetir um prazer antes sentido no seio materno (ou substituto). Ao sugar partes do próprio corpo como, por exemplo, o polegar, a pulsão da criança não se dirige a outra pessoa, mas ao próprio corpo, daí o fato de ser considerada autoerótica.

Ao nascer, a boca e os lábios são as zonas erógenas mais desenvolvidas do corpo do bebê. É por meio deles que a criança experimentará os primeiros momentos de prazer. Desta forma, a boca é a primeira parte do corpo que se efetiva como zona erógena.

Assim, nos primeiros anos de vida a sexualidade vai sendo formada por meio das primeiras experiências afetivas do bebê, cuja percepção é sensorial. A partir do contato com os pais e cuidadores a criança vai tecendo suas primeiras sensações sexuais, que serão base para formação de vínculos afetivos. A criança, então, por meio da pulsão sexual (libido) começará a buscar seus objetivos de satisfação e prazer. 
Ao mamar, o objetivo da criança parece não ser apenas a necessidade biológica de se alimentar. Neste ato o bebê procura se nutrir, além do leite materno, de uma relação afetiva com a mãe. Essa relação afetiva mesmo estando apoiada à satisfação alimentar, não se reduz unicamente a mesma.

A amamentação é, segundo KUPFER (2007, p. 39), “[...] entendida já como uma experiência sexual, geradora de prazer para a criança que suga e até mesmo para a mãe que amamenta. Não se veja aí qualquer sinal de perversão no sentido usual do termo, e sim um exercício prazeroso que o contato corporal proporciona".

Para o bebê a mãe é a figura que remete a satisfação pelo prazer do ato de mamar. Por intermédio deste ato, criança e mãe tornam-se um só ser. Por meio do seio e do leite a criança sente a mãe.

De acordo com Freud,

No chuchar ou sugar com deleite já podemos observar as três características essenciais de uma manifestação sexual infantil. Esta nasce apoiando-se numa das funções somáticas vitais, ainda não conhece nenhum objeto sexual, sendo autoerótica, e seu alvo sexual acha-se sob o domínio de uma zona-erógena. Antecipemos que essas características são válidas também para a maioria das outras atividades das pulsões sexuais infantis (FREUD, 1989a, p. 171).

Portanto, percebe-se que a sexualidade infantil surge ligada a necessidades orgânicas, que com o tempo levam a criança a procurar satisfação dos desejos no próprio corpo. Mesmo que a criança dirija suas fantasias a outra pessoa (objeto) - como por exemplo a mãe -, o prazer é buscado em seu próprio corpo.

A segunda fase de desenvolvimento da sexualidade infantil considerada por Freud é a fase "sádico-anal", que tem início por volta do segundo ano de vida da criança. Nesta fase a zona erógena anal ganha grande importância libidinal. A criança começa a estabelecer o controle dos esfíncteres, o que se transforma em uma nova fonte de prazer.

A criança descobre "que há matérias, identificadas a princípio como partes de seu próprio corpo, que dele se desprendem: as fezes. É natural que muitas dessas crianças desejem manipulá-las, coisa que a cultura se apressa em impedir [...]” (KUPFER, 2007, p. 43). As fezes adquirem para a criança grande valor. Vêm de dentro do seu próprio corpo, sendo vistas como uma extensão do mesmo. Além disso, proporcionam prazer ao serem produzidas e evacuadas.

A zona anal é fonte de grande excitabilidade. Para tirar proveito do prazer proveniente dessa parte erógena do corpo, a criança retém as fezes para que o acúmulo e a expulsão lhe deem sensação prazerosa. 
$\mathrm{O}$ ato de retenção e expulsão das fezes também adquire valor simbólico do amor da criança para com a mãe. As fezes são tidas pela criança como uma espécie de "presente" para assegurar o amor de sua mãe.

A fase que sucede a fase sádico-anal é a fase fálica, que veremos no próximo tópico, juntamente com a questão do Complexo de Édipo. Devido à repressão do Édipo, há, entre as fases fálica e genital, um período de latência.

Após a fase fálica temos a última fase, a fase genital, que é atingida na adolescência. Nesta fase o objeto de desejo não se encontra mais no próprio corpo, mas no outro. Agora as pulsões parciais são organizadas, unificadas e hierarquizadas por meio da primazia da zona genital. Apesar da primazia da zona genital nesta fase, as demais zonas erógenas não desaparecem, continuam sendo fonte de prazer.

\section{O complexo de Édipo e a fase fálica}

O complexo de Édipo ocorre aproximadamente entre os dois a cinco anos de idade. Segundo Freud é no complexo de Édipo que acontece a estruturação da personalidade do indivíduo. Na maior parte de seus estudos e observações Freud se atém ao Édipo masculino. Ele afirma que a mãe é o primeiro objeto de desejo do menino e o pai quem o impede que tenha o objeto desejado. Para conquistar a mãe o menino tenta imitar o comportamento do pai, internalizando normas por ele determinadas. Futuramente o menino abdica da mãe por "medo" do pai.

Freud trata especificamente do Édipo masculino, mas diz que esse processo também acontece com as meninas, sendo que as figuras de desejo e de identificação (pai e mãe) são invertidas.

A fase fálica é efetivamente definida por Freud no texto "A organização genital infantill" (1923). Ocorre, aproximadamente, entre os três a cinco anos de idade. Nesta fase há a erotização dos órgãos genitais e, por isso, as crianças demonstram a vontade de manipulação dos mesmos. Aqui é possível a observação e constatação do quanto a sexualidade encontra-se presente na criança.

Totalmente desprovida de vergonha, a criança manifesta satisfação em se despir e ver seus pares, surgindo curiosidade de ver os órgãos genitais e de manipulá-los. A criança não segue nem obedece a regras e normas morais nessa fase.

A fase fálica é também a fase em que acontecem, por parte da criança, as investigações sexuais, fruto do desejo de saber. Para Freud, 
Ao mesmo tempo em que a vida sexual da criança chega a sua primeira florescência, entre os três e os cinco anos, também se inicia nela a atividade que se inscreve na pulsão de saber ou de investigar. Essa pulsão não pode ser computada entre os componentes pulsionais elementares, nem exclusivamente subordinada à sexualidade [...] Suas relações com a vida sexual, entretanto, são particularmente significativas, já que constatamos pela psicanálise que, na criança, a pulsão de saber é atraída, de maneira insuspeitadamente precoce e inesperadamente intensa, pelos problemas sexuais, e talvez seja até despertada por eles. (FREUD, 1989a, p. 182)

O que inaugura o espírito observador e reflexivo da criança é o medo da perda do carinho de seus cuidadores pela ameaça - efetiva ou imaginada - da chegada de um bebê.

A partir do questionamento "De onde vêm os bebês?", a criança é levada a "criar" teorias para resolver o enigma de sua própria existência, iniciando, assim, indagações e investigações sobre a vida sexual.

Freud diz que

[...] a criança começa a refletir sobre o primeiro grande problema da vida e pergunta a si mesma: 'De onde vêm os bebês?' [...] Essa pergunta é, como toda pesquisa, o produto de uma exigência vital, como se ao pensamento fosse atribuída à tarefa de impedir a repetição de eventos tão temidos [...] (FREUD, 1989 c, p. 216, grifos do autor).

Para a criança, a origem dos bebês "Trata-se da questão mais remota e premente a atormentar a humanidade imatura. Os que sabem interpretar os mitos e as lendas podem identifica-lo no enigma que a Esfinge de Tebas apresenta a Édipo [...]" (FREUD, 1989b, p. 171)

Em 1908, no artigo "Sobre as teorias sexuais infantis", Freud discorre sobre as teorias que as crianças formulam. Segundo ele, quando a criança se volta para os que considera fonte de sabedoria (pais e cuidadores) pedindo uma resposta para seu enigma e recebe dos mesmos repreensões e ou respostas evasivas, não se satisfaz e continua tendo dúvidas, decepcionandose. Por causa de tal decepção e da desconfiança de que os adultos escondem algo, as crianças passam a fazer suas investigações em segredo e de maneira solitária.

A primeira teoria que formam na solidão de suas investigações é de que todos possuem um único órgão genital, o masculino. Nesta fase o órgão genital masculino é de suma importância e gera grande interesse - narcísico - por parte da criança.

O interesse e a importância dada ao órgão genital masculino geram indagações sobre o sexo do outro. A genitália feminina não é entendida como outro órgão sexual e sim vista como a ausência de um pênis, que a princípio, acredita-se que ainda irá crescer.

$\mathrm{Na}$ ânsia de descobrir como nascem os bebês, as crianças formulam a segunda teoria: a teoria cloacal. Esta teoria é formulada pelo desconhecimento do órgão sexual feminino. Pela 
observação concluem que o bebê se desenvolve dentro da mãe e supõem que o mesmo nasce por via anal. Se o bebê nasce pelo ânus, o homem também pode, assim como a mulher, ter um bebê. Portanto, é natural que nesta fase o menino venha a imaginar que possa vir a ter um bebê.

Depois de algum tempo atribuem para mesma questão o nascimento pelo umbigo ou pelo corte da barriga. Essas teorias podem ser relembradas na vida adulta, mas a teoria cloacal, facilmente aceita na infância, passa a ser reprimida posteriormente, por ser considerada repugnante.

Quando, acidentalmente, as crianças testemunham a relação sexual entre os pais, surge a terceira das teorias sexuais formulada pelas crianças, que é a "concepção sádica do coito". Este é entendido pela criança como ato violento imposto pelo mais forte ao mais fraco. Provavelmente, pelo fato de entender o ato sexual como ato violento, as crianças não relacionem o mesmo com a origem dos bebês.

Além das teorias descritas, algumas crianças ainda demonstram outra curiosidade relacionada a origem dos bebês, que é a natureza de "ser casado". Para a criança o casamento pode ser visto como uma espécie de atividade conjunta em que não existe pudor (micção, defecação, mostrar o traseiro, a mistura de sangue).

Tais teorias são concebidas pela criança de maneira espontânea nos primeiros anos de vida, sob a influência apenas da pulsão sexual. Essas teorias, segundo Freud, estão condenadas a ser abandonadas, sendo algumas esquecidas e outras recalcadas e fixadas no inconsciente. $\mathrm{O}$ processo de investigação é, então, abandonado - por volta do sexto ano de idade da criança devido à falsidade das teorias sexuais, a não aceitação da castração materna e pela dissolução do complexo de Édipo.

Por meio da dúvida sobre o nascimento surge o interesse pelo pênis, que se tornou zona erógena privilegiada nesta fase. Como a criança é desprovida de vergonha e pudor é comum o exibicionismo e a curiosidade pelo corpo do outro. Por meio das teorias sexuais infantis Freud postula a universalidade do pênis.

Para o menino todos possuem pênis e ao observar que o mesmo não é comum a todos (meninas), não vê a diferença entre os sexos e sim a falta, a princípio negando-a e acreditando que o pênis é pequeno e vai crescer. Só futuramente, diante de uma ameaça de castração, é que acredita que as meninas possuíam um pênis e o perderam.

A menina, de acordo com Freud, também comunga da teoria que ambos possuem pênis, havendo o interesse pelo mesmo. Tal interesse é logo seguido pela inveja do pênis, pois a mesma sente-se em desvantagem. 
No artigo “A organização genital infantil”, de 1923, Freud traz alguns acréscimos para a obra "Três ensaios sobre a teoria da sexualidade" e retoma a temática da primazia do pênis. $\mathrm{O}$ autor afirma desconhecer o processo nas meninas, podendo descrever apenas nos meninos.

A princípio, a distinção entre homem e mulher é percebida pelo menino, mas ele não vincula a diferença de órgãos genitais a essa distinção. Ao perceber a ausência do pênis nas meninas, o menino a entende como resultado de uma castração. Isso só ocorre a partir de uma ameaça de castração que o menino tenha vivenciado anteriormente.

Diante do órgão sexual feminino, o menino vê o resultado de uma castração e não a genitália feminina. Tal falta é encarada pelo menino como resultado de uma punição. Assim, "[...] agora, a criança se defronta com a tarefa de chegar a um acordo com a castração em relação a si própria [...]" (FREUD, 1989d, p. 182).

No entanto, para o menino, a mãe ainda possui um pênis. Apenas mais tarde, por meio das investigações sobre o nascimento do bebê e percebendo que apenas a mulher pode ter um, é que o menino "aceita" que a mãe perdeu o pênis, o que pode ser extremamente difícil para a criança.

A criança passa então a elaborar complicadas teorias que envolvem a troca do pênis por um bebê. O órgão genital feminino continua desconhecido. Segundo Freud, “[...] A antítese aqui é entre possuir um órgão genital masculino e ser castrado[...]” (FREUD, 1989d, p. 184 grifos do autor).

A descoberta de que a mãe é castrada tem grande efeito sobre a criança. Para o menino significa que ele também pode perder o seu. O menino passa, então, a temer a perda do pênis, já que para ele a menina tinha e perdeu. A menina, por sua vez, passa a culpar a mãe pelo fato de não possuir um pênis, passando a rejeitá-la, pois se a mãe não possui um pênis, não pode dar-lhe um. A menina passa, então, a ter o pai como objeto de amor, e não mais a mãe - seu primeiro objeto de amor. Ela espera receber do pai o falo que a mãe não pôde lhe dar.

Em relação à menina Freud vai tentar responder a alguns questionamentos dois anos depois, ao falar sobre a distinção anatômica entre os sexos.

Em 1924, com o texto intitulado “A dissolução do complexo de Édipo", Freud relaciona a organização fálica, o complexo de Édipo, o complexo de castração, a formação do superego e o período de latência. Tal relação justifica, segundo Freud, que a destruição do complexo de Édipo seja causada pela ameaça de castração.

O complexo de Édipo é, para a teoria psicanalítica, momento decisivo da formação do sujeito e ponto decisivo da sexualidade humana. 
A solução do complexo de Édipo nos meninos se dá por meio da ameaça de castração. Todavia, enquanto o menino teme sua efetivação, a menina, por sua vez, já lida com a castração como fato já existente.

No menino, que espera ter satisfação pulsional unindo-se a sua mãe - seu objeto de amor - o complexo de Édipo tem seu declínio a partir do complexo de castração. O medo de ser punido pelo pai com a castração - caso realize seu desejo em relação à mãe - leva o menino a abandonar tal desejo, dado o interesse narcísico que direciona para essa parte tão valorizada do próprio corpo.

Assim,

[...] Se a satisfação do amor no campo do complexo de Édipo deve custar à criança o pênis, está fadado a surgir um conflito entre seu interesse narcísico nessa parte de seu corpo e a catexia libidinal de seus objetos parentais. Nesse conflito, triunfa normalmente a primeira dessas forças: o ego da criança volta as costas ao complexo de Édipo (FREUD, 1989e, p. 221).

Percebe-se nas obras de Freud aqui analisadas, que o masculino continua a ser objeto prioritário dos estudos a respeito do Édipo. A teoria da primazia fálica continua sendo considerada universal por Freud. Para ele, a menina é castrada e precisa aceitar tal fato.

Freud diz que nas meninas também se desenvolve um complexo de Édipo, um superego e um período de latência. Há, na menina, organização fálica e complexo de castração, mas diferente da dos meninos. Inicialmente o clitóris é tido como um pênis diminuto. Assim, a menina sente-se injustiçada e inferiorizada na comparação com o pênis do menino, tendo por consolo a expectativa de que o mesmo crescerá. Depois de um tempo, já que o mesmo não crescera, a menina suspeita que já possuíra um pênis tendo-o perdido por meio da castração.

Nota-se uma diferença entre meninos e meninas em relação ao complexo de castração, pois "[...] a menina aceita a castração como um fato consumado, ao passo que o menino teme a possibilidade de sua ocorrência” (FREUD, 1989e, p. 223). Assim, a ameaça para a menina não é a perda do pênis, e sim a ameaça da perda do amor.

Para Freud o desenvolvimento correspondente na menina é obscuro e cheio de lacunas, apesar de achar que a solução do complexo de Édipo nas meninas é mais fácil. Para ele, a menina apenas precisa assumir o lugar da mãe, adotando uma atitude feminina perante o pai.

Com a renúncia do pênis e a aceitação de não o possuir, a menina o trocaria pelo desejo de ter um filho. O complexo de Édipo nas meninas chega ao auge no desejo de receber do pai um bebê de presente, ou seja, um filho. Não sendo realizado tal desejo o complexo vai sendo, gradativamente, abandonado. $\mathrm{O}$ mesmo permanece no inconsciente. 
Freud apresenta algumas outras reflexões sobre a sexualidade feminina no artigo "Algumas consequências psíquicas da distinção anatômica entre os sexos", de 1925. A partir das diferenças anatômicas entre os sexos Freud fala de suas consequências psíquicas, pois tal distinção gera diferentes resultados psíquicos para cada sexo.

Para as meninas, sendo a própria castração evidente, o complexo de castração tem sua origem na falta, que não é fácil de ser aceita por ela. A menina vai culpar a mãe e se sentir inferiorizada. Na Conferência XXXIII sobre Feminilidade (1933), nas Novas Conferências Introdutórias, Freud diz que além de as meninas responsabilizam a própria mãe pela falta de pênis, não a perdoam por se sentirem em desvantagem. Vai, assim, aproximando-se do pai. Na menina, o complexo de castração é, portanto, a porta de entrada para o complexo de Édipo.

Para o menino é difícil confrontar-se com a falta do órgão que ele tanto exalta e, assim, o complexo de castração torna-se a saída do complexo de Édipo. Para ambos o complexo de castração apresenta-se como um problema, mas de forma distinta.

É necessário ressaltar, que dada a sua plasticidade, o Édipo acontece de maneiras distintas nos sujeitos. Não há uma única maneira de atravessar o complexo de Édipo. Esse é um processo interno individual e único.

Com a dissolução do complexo de Édipo a criança entra no período de latência, período de reorganização interna. Nessa fase há o declínio da sexualidade infantil até a puberdade. O declínio aparece também a partir do aparecimento de certos "diques", que limitam as pulsões sexuais, como o sentimento de vergonha, nojo, repugnância. Tais diques são construídos com a contribuição da Educação.

Com a repressão do Édipo a energia libidinal se afasta de seus objetivos sexuais. Todavia tal energia não desaparece nem finda, sendo necessário ser deslocada para outros objetivos. Através de um processo chamado sublimação essa energia vai sendo "canalizada" para outros fins: o desenvolvimento social e intelectual da criança. Assim, a sublimação seria o desvio das forças pulsionais sexuais para realizações culturais e aceitas socialmente.

\section{O esclarecimento sexual e a amnésia infantil}

Segundo Freud não há motivo algum para se ocultar questões relacionadas à sexualidade das crianças. Em uma carta ao Dr. M. Fürst, em 1907, demonstra-se perplexo com o fato de ainda se tentar ocultar das crianças fatos relacionados à sexualidade. Para o autor tal fato decorre do pudor, da má consciência e da ignorância dos educadores. Reitera na carta que a criança, 
desde seu nascimento, experimenta sensações sexuais e é dotada de curiosidade, desde a mais tenra idade, relativa às questões sexuais.

Para Freud, não “[...] parece haver uma única razão de peso para negar às crianças o esclarecimento que sua sede de saber exige. [...] Se as dúvidas que as crianças levam aos mais velhos não são satisfeitas, elas continuam a atormentá-las em segredo [...]” (FREUD, 1989b, p. 142)

A falta de sinceridade dos adultos para com os questionamentos infantis pode, de certa forma, comprometer o futuro intelectual das crianças. As mentiras inventadas à criança diante de inquietações, questionamentos e investigações sexuais podem causar certo conflito psíquico na mesma, abalando sua confiança nos pais (ou cuidadores). Para Freud, o ocultamento da verdade é um grande erro, que trará consequências futuras.

Por vezes, a negativa em se falar de "determinados" assuntos por ocorrer por medo de, prematuramente, despertar o interesse da criança para os assuntos sexuais. Todavia, o ocultamento não garante a "pureza" infantil na qual muitos acreditam. O ocultamento, pelo contrário, intensifica a curiosidade da criança.

Freud diz que, se satisfeita adequadamente em cada fase da aprendizagem, de maneira gradual, a curiosidade da criança não atinge uma intensidade exagerada, para além de sua fase de desenvolvimento.

A negação do esclarecimento sexual às crianças, sua tentativa de ocultamento e a dificuldade do adulto em lidar com a sexualidade infantil relacionam-se à amnésia infantil, descrita por Freud em 1905, nos "Três Ensaios".

A amnésia infantil oculta as lembranças da própria vida sexual do adulto enquanto criança e as experiências sexuais vivenciadas nesse período. $\mathrm{O}$ fato de não se lembrar, na vida adulta, de episódios da primeira infância acontece em virtude do recalcamento das vivências sexuais infantis.

A recusa e a objeção da existência da sexualidade infantil estão atreladas às barreiras (nojo, vergonha, repugnância) que se formam por meio de padrões morais existentes contra a sexualidade infantil - presentes no sujeito já no período de latência - a favor de atitudes e sentimentos socialmente valorizados e aceitos.

Todo ser humano passou pela sexualidade quando criança, porém se esqueceu de tudo, tendo tais vivências ficado do inconsciente de cada um. A criança, ao manifestar sua sexualidade, mostra isso ao adulto, que a recrimina. 
A verdade é que o ser humano carrega por toda a vida as marcas dos traumas, conflitos e desejos da criança que foi. A questão é que "A sexualidade infantil confronta o adulto com sua própria infância perdida [...]" (ZORNIG, 2008, p. 77).

Portanto, a amnésia infantil é um período esquecido e ao mesmo tempo determinante na vida do indivíduo. De certa forma, o adulto sempre portará o infantil que o compõe e "[...] Cabe ao adulto não interpretar a sexualidade infantil atribuindo-lhes significados adultos, mas sim, reconhecer sua forma de comunicação, sua demanda de amor” (ZORNIG, 2008, p. 76).

\section{Considerações finais}

O conceito de sexualidade, em especial de sexualidade infantil, foi modificado profundamente por Freud no início do século XX. O autor inovou a concepção de sexualidade infantil e ampliou o próprio conceito de sexualidade, causando uma mudança de paradigmas.

Como identificou toda busca de prazer com a libido, identificando-a como energia vital presente em todo ser humano desde seu nascimento, causou estranheza e recusa por parte da sociedade de seu tempo.

Ainda hoje a sexualidade continua sendo vista, por muitos, como tema polêmico, cuja exposição geralmente gera constrangimentos. Está, ainda, impregnada de tabus, mitos e preconceitos.

É urgente que se entenda, a partir da psicanálise, que a sexualidade não está e nem se encontra fora do sujeito, é algo inerente ao ser humano. Está presente desde os primeiros anos de vida e vai sendo formada nas relações estabelecidas com o outro e com o mundo social. A sexualidade não engloba apenas a reprodução e o prazer ligado aos genitais.

Mesmo não sendo a criança o alvo a partir do qual inicia suas pesquisas, ao escrever "Três ensaios sobre a teoria da sexualidade", Freud atribui à infância um lugar privilegiado, através de uma sistematização teórica.

O conceito de sexualidade defendido por Freud não se reduz aos genitais, nem tampouco se resume ao ato sexual, indo além da necessidade fisiológica, relacionando-se com a simbolização do desejo.

Ao caracterizar a infância como perverso-polimorfa, polivalente e autoerótica, apontando que o sujeito busca e obtém a sensação de prazer sexual em qualquer parte do próprio corpo, sem necessariamente haver união dos genitais, Freud lança luz ao ser humano como sujeito de desejos. 
É necessário que sejam esclarecidas as dúvidas infantis relacionadas à questão da sexualidade. É preciso não reprimir suas manifestações sexuais, ajudando as crianças a lidarem com sua organização libidinal instável em que se encontram, auxiliando-as, assim, a se estruturarem como sujeitos adultos razoavelmente saudáveis.

Apesar de Freud ter formulado há mais de um século a teoria da sexualidade infantil, propondo a noção de uma infância diferente e afastada da tradicional ideia de pureza infantil, revelando uma criança dotada de desejos, afetos e conflitos, é possível perceber, ainda nos dias atuais, a dificuldade de aceitar as formulações do fundador da psicanálise sobre o tema. Infelizmente há, ainda, muitos embaraços, por parte dos adultos, em relação à sexualidade infantil.

Se por um lado Freud afasta a visão de uma inocência infantil, por outro lado, esse mesmo conceito considera a infância como período importante da vida, pois aponta que a vida infantil determina as escolhas que serão feitas na vida adulta. Psiquicamente, o infantil permanece, de alguma forma, no adulto por toda sua vida.

Os elementos da teoria de sexualidade proposta por Freud são, de certa maneira, impregnados pela ideologia predominante na sociedade de seu tempo. Uma sociedade patriarcal, machista. Mesmo sendo um homem de seu tempo, não se pode negar as inúmeras contribuições deixadas por Freud, que propôs uma teoria da sexualidade infantil revolucionária para sua época e que ainda hoje, mais de um século depois, não conseguiu cumprir seu papel. A criança é ainda concebida como um "anjo", um ser assexuado e ainda não se conseguiu implicar a visão freudiana de criança. Apesar da grande contribuição da psicanálise, não enxergamos essa criança, que é um ser ambivalente.

Não é mais possível, depois das teorias de Freud, ignorar que a criança é um ser sexuado. A importância atribuída, em sua obra, à sexualidade infantil deve-se ao reconhecimento do valor estruturante desta para o ser humano, pois " [...] as teorias sexuais infantis permitem à criança interpretar o enigma de sua existência [...]” (ZORNIG, 2008, p. 76).

\section{REFERÊNCIAS}

FREUD, S. Três ensaios sobre a teoria da Sexualidade. In: Edição standard brasileira das obras psicológicas completas de Sigmund Freud (Vol. 7). 3.ed. Rio de Janeiro: Imago. 1989a. (Originalmente publicado em 1905).

FREUD, S. O Esclarecimento Sexual das Crianças. In: Edição standard brasileira das obras psicológicas completas de Sigmund Freud (Vol. 9, pp. 137-144). 3.ed. Rio de Janeiro: Imago. 1989b. (Originalmente publicado em 1907). 
FREUD, S. Sobre as Teorias Sexuais das Crianças. In: Edição standard brasileira das obras psicológicas completas de Sigmund Freud (Vol. 9, pp. 213-228). 3.ed. Rio de Janeiro: Imago. 1989c. (Originalmente publicado em 1908).

FREUD, S. A organização genital infantil: uma interpolação na teoria da sexualidade. In: Edição standard brasileira das obras psicológicas completas de Sigmund Freud (Vol. 19). 3.ed. Rio de Janeiro: Imago. 1989d. (Originalmente publicado em 1923).

FREUD, S. A dissolução do complexo de Édipo. In: Edição standard brasileira das obras psicológicas completas de Sigmund Freud. 3.ed. Rio de Janeiro: Imago. 1989e.

(Originalmente publicado em 1924). (V. 19, p. 217-224)

FREUD, S. Algumas consequências psíquicas da distinção anatômica entre os sexos. In: Edição standard brasileira das obras psicológicas completas de Sigmund Freud 3.ed. Rio de Janeiro: Imago. 1989f. (Originalmente publicado em 1925). (Vol. 19, p. 309-320).

FREUD, S. Conferência XXXIII: Feminilidade. Novas Conferências Introdutórias sobre Psicanálise. In: Edição standard brasileira das obras psicológicas completas de Sigmund Freud. 3.ed. Rio de Janeiro: Imago. 1989g. (Originalmente publicado em 1933). (Vol. 22)

KUPFER, M. C. M. Freud e a educação: o mestre do impossível. 3.ed. São Paulo: Scipione, 2007.

ZORNIG, S. M. A. As teorias sexuais infantis na atualidade: algumas reflexões. Psicologia em Estudo, Maringá 34 (1), p. 73-77, jan./mar. 2008.

\section{Como referenciar este artigo}

BOROTO, Ivonicleia Gonçalves; SENATORE, Regina Célia Mendes. A sexualidade infantil em destaque: algumas reflexões a partir da perspectiva freudiana. Revista Ibero-Americana de Estudos em Educação, Araraquara, v. 14, n. esp. 2, p. 1339-1356, jul., 2019. E-ISSN: $1982-$ 5587. DOI: 10.21723/riaee.v14iesp.2.12583

Submetido em: 25/09/2018

Revisões requeridas: 18/03/2019

Aprovado em: 30/03/2019

Publicado em: 25/06/2019 